\title{
Parámetros para el monitoreo de la biota fúngica interior en un área subtropical
}

\author{
Fernández, Mariana S. ${ }^{\text {; }}$ Mangiaterra, Magdalena L. ${ }^{\text {; }}$ Giusiano, Gustavo E. ${ }^{1,2}$
}

En la práctica médica tienen cada vez más importancia las enfermedades causadas por hongos oportunistas adquiridas en ambientes hospitalarios. La mayor gravedad se presenta en lugares de alto riesgo, como guarderías, residencias de ancianos, quirófanos y Unidades de Terapia Intensiva $(\mathrm{UTI})^{(1)}$. En los ambientes internos la proliferación de los contaminantes biológicos (principalmente hongos) se da en las zonas húmedas como floreros, humedad de las paredes, humidificadores, macetas con plantas y en las fibras capaces de retenerlos, a saber, filtros de aire, alfombras, cortinas de tela, pinturas porosas, etc. Estos contaminantes son transportados por visitantes, personal hospitalario, alimentos contaminados, sondas urinarias, equipos de terapia intravenosa e instrumentos mal esterilizados ${ }^{(2,3,4)}$. Entre los agentes más destacados se encuentran los mohos, Aspergillus, Penicillium, Fusarium, Alternaría, Cladosporiutn, Acremonium, Stachybotrys, Curvularia y Photna y las levaduras Candida, Cryptococcus, Rhodotorula y Geotrichum ${ }^{(1,5)}$. Por lo tanto, la vigilancia epidemiológica en los hospitales es necesaria para evitar infecciones fúngicas. Para ello, es imprescindible conocer la calidad del aire confinado, realizando un recuento selectivo de levaduras y de mohos, como el más elemental mecanismo de prevención de enfermedades ${ }^{(1,6,7)}$.

Para poder relacionar los resultados propios con los obtenidos por otros autores es necesario que el procedimiento metodológico se asemeje a los estándares. En relación a la aeromicología, sólo en los países donde la aerobiología está organizada, existen protocolos que facilitan el desarrollo de una metodología común ${ }^{(8)}$. Debido a diferencias biogeográficas y climáticas, la biota fúngica de una zona subtropical es, en espacial, cuantitativamente diferente a la de los países donde se han establecido los protocolos. Con el fin de obtener resultados comparables, siguiendo los procedi-

\footnotetext{
${ }^{1}$ Instituto de Medicina Regional. Universidad Nacional del Nordeste. Av. Las Heras 727, 3500 Resistencia, Argentina.

${ }^{2}$ Cátedra de Microbiología, Parasitología e Inmunología. Facultad de Medicina. UNNE. Moreno 1240. 3400 Corrientes, Argentina.

Correo electrónico: mariana_fl9@hotmail.com
}

mientas estándares, se buscaron los parámetros metodológicos para establecer la biota fúngica en ambientes confinados (de internación) de una zona subtropical.

Las muestras se tomaron en la UTI del Hospital Pediátrico "Juan Pablo II" de la ciudad de Corrientes, Argentina. La sala se encuentra en el primer piso, mide 13 x 20m, con el eje mayor orientado en sentido norte-sur. Sobre las paredes del Este y el Oeste hay ventanas con vidrios fijos. En el centro de la sala está el sector de enfermería, limitado por una pared de 1,20 m de alto. En la sala hay cinco piletas de lavado, tres sobre la pared Este, una sobre la pared Oeste y otra dentro del sector de enfermería.

La recolección de propágulos aéreos se realizó mediante un colector de aire Surface Air Sampler, P.B.I. Intenational super $100^{(\mathrm{R})}$ (SAS), que tiene rangos variables de aspiración de flujo de aire, de 100 a 1000 1/min. El aire es dirigido hacia la superficie de una placa de Petri que contiene el medio de cultivo seleccionado. Para elegir el horario más adecuado se tomaron muestras a las 8:00 a.m., a las 12:00 a.m. y a las 17:00 p.m. En todas las muestras se siguió un diseño diagonal ${ }^{(8)}$, tomando 5 puntos, 4 en los extremos y uno en el sector enfermería. Con el fin de comparar, tanto la carga como la diversidad fúngica interna respecto de un área externa, se muestreó el ambiente inmediato a la puerta de acceso, que se consideró como blanco (Bl) (Figura 1). Para determinarla altura más conveniente para ubicar el colector se realizaron muestreos a 0,50 m y $1,50 \mathrm{~m}$ del suelo. Para establecer el volumen de aire se efectuaron colectas con 400 litros, 300 litros y 200 litros. Como medio de impacto se utilizó agar papa dextrosa con cloranfenicol 250mg/1 (PDA/ATB), en placas de Petri de 9mm.

Por el método del hisopo (8), se tomaron muestras de superficie (Sup) de las mesadas del sector enfermería y de los aparatos de control de 2 camas (Figura 1). En ese momento se sembró en PDA/ATB, contenido en placas de Petri de 9 $\mathrm{mm}^{(2)}$.

La toma de muestra se realizó simultáneamente por los dos métodos.

Las placas obtenidas de ambos tipos de muestreo se incubaron a $28^{\circ} \mathrm{C}$ durante $72 \mathrm{hs}$; al cabo de las cuales se rea- 
lizó el recuento de las colonias por placa. En ese momento, cada colonia se repicó para su posterior identificación en tubos con PDA/ATB, los cuales se incubaron a $28^{\circ} \mathrm{C}$ y $37^{\circ} \mathrm{C}$, entre 7 y 10 días.

Para determinar las unidades formadoras de colonias por metro cúbico de aire $\left(\mathrm{UFC} / \mathrm{m}^{3}\right)$, conociendo el número de colonias por placa (NC), el flujo de aire y el tiempo de muestreo que se ha usado (NU), se aplicó la fórmula siguiente $^{(9)}$ :

$$
\mathrm{N}^{\mathrm{o}} \mathrm{UFC} / \mathrm{m}^{3}=\frac{\mathrm{NC} \times 1000}{\mathrm{NU}}
$$

Se eligió tomar las muestras al mediodía porque hay menor movimiento del personal dentro de las salas y está fuera de los horarios de visita. Además, se vio que a esta hora la concentración fúngica era mayor.

La altura más conveniente resultó la de 1,50 metros del suelo, ya que a esta distancia no se levantaban las conidias depositadas en el suelo, obteniéndose una muestra más representativa del aire de cada sala.

El volumen eficiente fue de 200 litros, dado que en todos los muéstreos realizados con 400 y 300 litros resultó imposible el recuento de las colonias, ya que crecían encimadas.

Se decidió muestrear en otoño y en primavera, porque en esta región son los períodos más y menos lluviosos respectivamente. Además, en trabajos previos realizados en ambientes exteriores en esta zona, en otoño obtuvieron mayor carga fúngica que en primavera ${ }^{(10)}$. Las muestras se
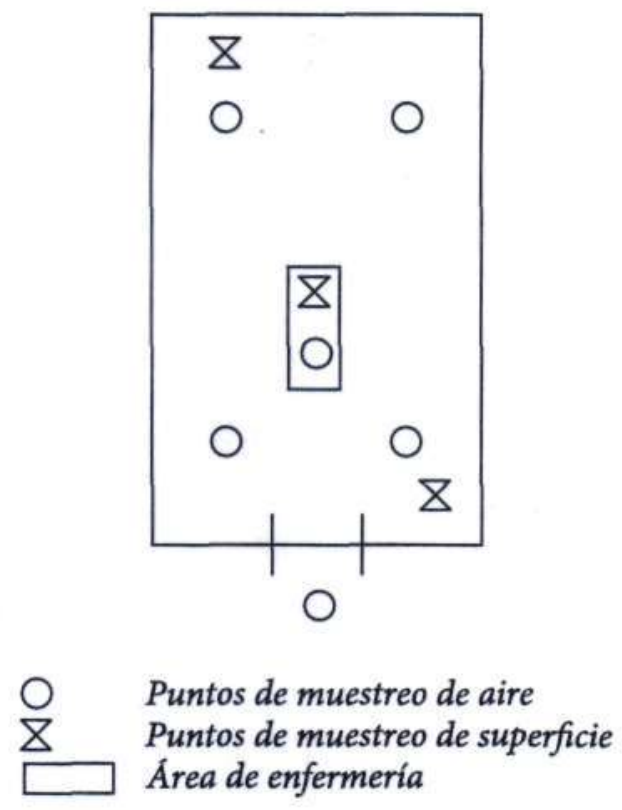

Figura 1. Plano de la UTI pediátrica y zonas de muestreos tomaron cada 15 días, después de la limpieza habitual d la Unidad.

Si bien la interpretación de los resultados en los muestreos de aire es problemática, debido a que el nivel de propágulos aéreos varía por las fluctuaciones de temperatura por la humedad relativa y por las corrientes de aire; los resultados obtenidos en este trabajo nos permitirán comparar los valores obtenidos en una zona subtropical, como la ciudad de Corrientes, con aquellos datos generados en una región biogeográfica y climática diferente.

\section{BIBLIOGRAFÍA}

1. Flannigan, B. \& Miller, D. Health iraplications of fungi in indoor environments - an overview. En: Samson RA; Flannigan B; Flannigan ME; Verhoeff AP, Adán OCG, Hoekstra ES, eds. Health implication of fungi in indoor environments. Air quality monographs 1994; 2: 3-11.

2. Zumbado, H. Epidemiología y Control Microbiología) de Infecciones. En Manual de Procedimientos en Microbiología Clínica, Editor: Henry D. Isenberg. 2004.

3, Anaissie E. Opportunist mycoses in the immunocompromised host: a cáncer and review. Clin Infect Dis 1992; 14:43-53.

4. Fridkin S, farvis W. Epidemiology of nosocomial fungal infections. Clin Microbiol Rev 1996; 9:499-511.

5. Fernández, M., Mangiaterra, M., Giusiano, G. Micobiota ambiental en la Unidad de Terapia Intensiva de un Hospital Pediátrico. Boletín Micológico 2009; 24: 41-49.

6. Alfano, V.; Visciano, A.; Liguori, G. Aspetti pratici del monitoraggio microbiologico ambiéntale. Biología Clinica 2007; 2:30-34.

7. UNICHIM. Manuale N. 203. Rischio biológico in ambienti "indoor" Inquadramento della problemática e strategia di controllo e prevenzione. Associazione per l'Unincazione nel Settore dell'indutria Chimica. Federata all'UN1. Milano 2009.

8. Rojas, T.I.; Martínez, E.; Aira, M.J.; Almaguer, M.. Aeromicota de ambientes internos: Comparación de métodos de muestreo. Boletín Micológico 2008; 23:67-73.

9. Martí Solé, M.C. 1993. NTP 299: Método para el recuento de bacterias y hongos en aire, http://www.mtas.es/insht/ntp/ntp_299.htm

10. Esquivel, P.; Mangiaterra, M.; Giusiano, G.; Sosa, M.A. Microhongos anemófilos en dos ciudades del nordeste argentino. Boletín Micológico $2003 ; 18: 21-28$. 